[CONTribution From the Chemical Laboratory OF the UNIVERSity OF Wisconsin.]

\title{
THE DETERMINATION OF FERROUS IRON IN SILICATES BY TITRATION WITH DICHROMATE.
}

By O. L. BARNEBEY.

Received May 31, 1915.

The permanganate titration has been used for the determination of ferrous iron in silicates almost, if not quite, exclusively. This study introduces dichromate for this purpose in a method which is proven to be accurate.

A dichromate titration of the ferrous iron obtained by extraction of a silicate with hydrofluoric acid has several points in its favor. A dichromate solution is more stable than the permanganate solution, which is ordinarily used for this purpose. Moderate quantities of hydrochloric acid do not interfere with the dichromate titration, thus allowing the use of this acid, if it is desired, in the extraction process. Dichromate is not as easily reduced by organic matter as is permanganate. However, ferrous iron cannot be titrated accurately with dichromate in a hydrofluoric acid solution. Further, ferrous iron in fluoride solution oxidizes so rapidly that a slow titration, such as accompanies the use of an outside indicator on a spot plate, may introduce a considerable error.

Boric acid ${ }^{1}$ has been found to remove hydrofluoric acid from solution, interaction forming metafluoboric acid. The use of boric acid also permits an accurate titration of ferrous iron to be made with dichromate (Table I).

In Experiments 3 and 4 the dichromate was added until, upon placing a drop of the solution in contact with a drop of $0.05 \%$ potassium ferricyanide solution, the development of color on the spot plate was very slow. The time required for the development of the ferrous iron test is designated in the table. More dichromate was then added and another test applied. The more the dichromate added the longer became the time required for the development of the color test. These two experiments show that an enormous error may be introduced by the presence of fluorides. In Experiments 5 and 6 boric acid was present and hydrochloric acid absent. In 7 and 8 boric acid was added previous to titration in the presence of hydrochloric acid. Excellent results were obtained in the four experiments. Constant quantities of iron in the presence of constant amounts of hydrochloric acid in constant volume of solution were titrated with variable amounts of hydrofluoric acid both with and without the addition of boric acid in excess preceding titration (Experiments 9-20 inclusive). Below approximately o. I5 $N$ the effect of hydrofluoric acid is found to be small when titrating moderate amounts of iron. Above 0.15 $\mathrm{N}$ the error becomes progressively larger as the concentration of the

\footnotetext{
1 Barnebey, This Journal, 37, I48I (1915).
} 
Table I.-Titration of Iron with Dichromate in Hydrochloric and HydroFLUORIC ACID SOLUTIONS.

I cc. $\mathrm{K}_{2} \mathrm{Cr}_{2} \mathrm{O}_{7}=0.00638 \mathrm{I}$ g. FeO. 1

r cc. $\mathrm{FeSO}_{4}=1.007032$ g. $\mathrm{FeO}$.

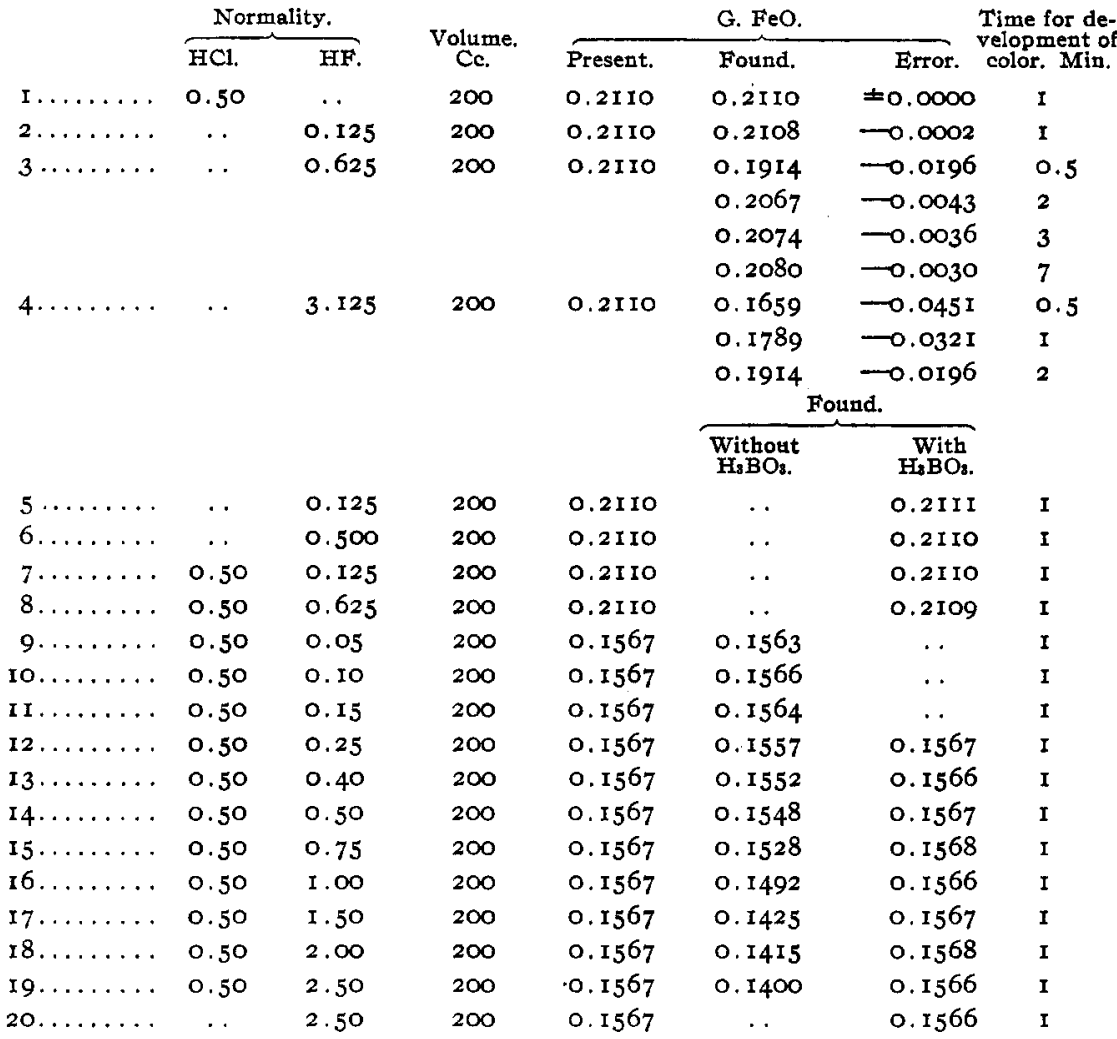

hydrofluoric acid increases. The addition of boric acid removes this fluoride effect and permits excellent results to be obtained even when the concentration of the hydrofluoric acid is $2.5 \mathrm{~N}$.

\section{Sensitiveness of the Ferricyanide Test for Ferrous Iron.}

In previous work the author has frequently observed that variation of the strength of hydrochloric acid has a tendency to change the sensitiveness of the ferricyanide test for small amounts of ferrous iron. To ascertain the extent of this effect a series of experiments was performed (Table II). The effect of hydrofluoric acid was also made a matter of study in this series. In each experiment the acid, with or without added ferric chloride, was diluted to $200 \mathrm{cc}$. volume and standard ferrous sulfate added

1 The dichromate solutions used in this work were standardized against pure electrolytic iron and the ferrous iron solutions were standardized with the dichromate in each series of experiments, using ferricyanide as indicator. 
until one drop of the solution gave the color test with ferricyanide on a porcelain spot plate.

The column "test sensitiveness" gives the sensitiveness computed upon the basis of actual parts of ferrous iron contained in the solution. In order to obtain the sensitiveness in the spot plate reaction the "test sensitiveness" results should be multiplied by twenty, inasmuch as twenty drops of the solution were equivalent to one $c c$. and only a single drop of the solution was removed for the test with ferricyanide. One minute was the time allowed for the color to develop. Preliminary study had indicated that not less than 0.04 or more than $0.10 \%$ potassium ferricyanide gives the best results in the test for ferrous iron. In the tests here recorded three series of tests were used as checks upon each other, involving the use of $0.04,0.06$ and $0.08 \%$ potassium ferricyanide solutions.

TABIE II.-Sensitrveness of the Ferricyanide Test for Ferrous Iron.

I cc. $\mathrm{FeSO}_{4}=0.005222 \mathrm{~g}$. Fe.

\begin{tabular}{|c|c|c|c|c|c|c|}
\hline & \multicolumn{2}{|c|}{ Normality. } & \multirow{2}{*}{$0.1 \mathrm{~N} \mathrm{FeCl}}$. & \multirow{2}{*}{$\begin{array}{c}\text { Volume. } \\
\text { Cc. }\end{array}$} & \multirow{2}{*}{$\begin{array}{c}\mathrm{G} . \mathrm{Fe} \\
\text { required. }\end{array}$} & \multirow{2}{*}{$\begin{array}{l}\text { Test sensi- } \\
\text { tiveness. } \\
\text { One part in }\end{array}$} \\
\hline & $\mathrm{HCl}$. & HF. & & & & \\
\hline $\mathbf{r} \ldots \ldots \ldots \ldots \ldots$ & $\ldots$ & . & $\ldots$ & 200 & 0.0002 & $1,000, \infty 00$ \\
\hline $2 \ldots \ldots \ldots \ldots \ldots$ & 0.30 & $\cdots$ & . & 200 & 0.0005 & 400,000 \\
\hline $3 \ldots \ldots \ldots \ldots$ & 0.60 & . & . & 200 & 0.0010 & $200, \infty 00$ \\
\hline $4 \ldots \ldots \ldots \ldots$ & 1.20 & . & . & 200 & 0.0019 & 105,000 \\
\hline $5 \ldots \ldots \ldots \ldots \ldots$ & 1.60 & . & . & 200 & 0.0025 & 80,000 \\
\hline $6 \ldots \ldots \ldots \ldots \ldots$ & 3.20 & $\ldots$ & . & 200 & 0.0060 & 33,000 \\
\hline $7 \ldots \ldots \ldots \ldots$ & $\ldots$ & 0.05 & . & 200 & 0.0020 & 100,000 \\
\hline $8 \ldots \ldots \ldots \ldots$ & . & 0.15 & . & 200 & 0.0045 & $44, \infty 00$ \\
\hline $9 \ldots \ldots \ldots \ldots$ & $\cdots$ & 0.25 & . . & 200 & 0.0068 & 30,000 \\
\hline Io............... & . & 0.50 & .. & 200 & 0.0094 & $21, \infty 00$ \\
\hline II $\ldots \ldots \ldots \ldots \ldots$ & . & I.25, & . & 200 & 0.0151 & $13, \infty$ \\
\hline $12 \ldots \ldots \ldots \ldots \ldots$ & . & 2.50 & . & 200 & 0.0234 & 8,500 \\
\hline $13 \ldots \ldots \ldots \ldots$ & . & . & $\cdots$ & 200 & 0.0002 & $x, \infty 00, \infty$ \\
\hline $14 \ldots \ldots \ldots \ldots \ldots$ & 0.25 & . & 5 & 200 & 0.0003 & 670,000 \\
\hline $\mathrm{I}_{5} \ldots \ldots \ldots \ldots \ldots$ & 0.50 & . & 5 & 200 & 0.0002 & $1,000, \infty 00$ \\
\hline I6............. & 1.00 & . & 5 & 200 & 0.0002 & $1,000,000$ \\
\hline $17 \ldots \ldots \ldots \ldots \ldots$ & 2.50 & . & 5 & 200 & 0.0004 & 500,000 \\
\hline $18 \ldots \ldots \ldots \ldots \ldots$ & $\cdots$ & 0.05 & 5 & 200 & 0.0003 & $670, \infty 00$ \\
\hline $19 \ldots . . . \ldots \ldots$ & . & 0.10 & 5 & 200 & 0.0008 & $250, \infty 00$ \\
\hline $20 \ldots \ldots \ldots \ldots \ldots$ & . & 0.25 & 5 & 200 & 0.0022 & $90, \infty 00$ \\
\hline $2 \mathbf{2 1} \ldots \ldots \ldots \ldots$ & . & 0.50 & 5 & 200 & 0.0104 & 19,000 \\
\hline $22 \ldots \ldots \ldots \ldots \ldots$ & . & 1.00 & 5 & 200 & 0.0135 & 15,000 \\
\hline $23 \ldots \ldots \ldots \ldots$ & . & 2.50 & 5 & 200 & 0.0140 & 14,000 \\
\hline $24 \ldots \ldots \ldots \ldots$ & . & 0.50 & 10 & 200 & 0.0025 & $80, \infty 00$ \\
\hline $25 \ldots \ldots \ldots \ldots \ldots$ & . & 1.00 & ro & 200 & 0.0059 & 34,000 \\
\hline $26 \ldots \ldots \ldots \ldots \ldots$ & . & $0.5^{\circ}$ & 40 & 200 & 0.0010 & 200,000 \\
\hline $27 \ldots \ldots \ldots \ldots \ldots$ & $\ldots$ & $1 . \infty$ & 40 & 200 & 0.0020 & 100,000 \\
\hline
\end{tabular}

Experiments $1-6$ and $7-12$ show a progressive lowering of the sensitiveness of the ferrous iron test as the normality of the hydrochloric and hydrofluoric acid increases. However, the addition of ferric iron to the 


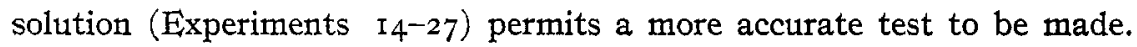
(The ferric chloride was entirely free from any trace of ferrous iron.) Sulfuric and phosphoric acids give an effect similar to hydrochloric acid. Using $2.5 N$ sulfuric acid, $0.004 \mathrm{~g}$. of iron was required in $200 \mathrm{cc}$. vol. to give the ferrous iron test on the spot plate. This corresponds to a solution sensitiveness of one part in fifty thousand and a spot plate sensitiveness of one part in a million. With $2.5 \mathrm{~N}$ phosphoric acid (computed on the basis of three replaceable hydrogen atoms), $0.006 \mathrm{~g}$. of iron was necessary, corresponding to one part in thirty-three thousand and six hundred sixty thousand parts for the solution and spot plate sensitiveness, respectively. The addition of ferric chloride to the solution or spot plate, especially the latter, brings out the test with a very small amount of ferrous iron, $0.0002 \mathrm{~g}$. being easily detected, hence yielding a solution sensitiveness of one part in a million and a spot plate sensitiveness of one part in twenty million parts of solution. Other salts such as sodium, ammonium, potassium, barium and aluminum chlorides do not have an effect similar to ferric chloride. It does not seem improbable that the ferrous chloride in strong acid solution reduces in part the ferri- to ferrocyanide. ${ }^{1}$ The ferrocyanide then reacts with the ferric iron present to form a salt similar to or identical with "Prussian Blue." "Prussian Blue" has a tendency to decompose in hydrochloric acid solution forming ferric chloride and hydroferrocyanic acid. Now the addition of ferric iron to such a solution tends to form a ferri-ferrocyanide by mass action, hence causing the color to reappear. When the hydrochloric acid is weak the reaction on the spot plate proceeds normally, yielding a ferrous ferricyanide. However, the reactions are undoubtedly complex in character, as indicated by the differences of colors, green to blue, obtained on the spot plate. It matters not which blue or greenish blue is formed if the appearance of color can be obtained by the presence of a very slight excess of ferrous iron in such a manner as to constitute a reliable test.

The effect of diminishing sensitiveness of the ferrous iron test in strong hydrochloric and hydrofluoric acid solutions was tried in the titration of small amounts of iron. In this series of experiments the standard solutions of ferric chloride, ferrous chloride and potassium dichromate were approximately o.I $N$ (Table III).

In the presence of $2.5 \mathrm{~N}$ hydrochloric acid small amounts of ferrous iron cannot be titrated directly with accuracy (Experiments I, 4, 5 and 8). Experiments 2, 6 and 9 show that the addition of ferric chloride to the solution of ferrous iron permits a correct titration to be made, even when the hydrochloric acid is $2.5 \mathrm{~N}$. As the quantity of ferrous iron to be titrated increases, thus forming more ferric iron in solution, the titration becomes more accurate. Experiments II, I2, 13 and $I_{4}$ indicate that

${ }^{1}$ See also Hofmann, Heine and Höchteln, Ann., 337, I (I904). 
TABLE III.-EFFECT OF STRONG HydROChLORIC AND HydROFLUORIC ACIDS ON THE Titration of Smali amounts of Ferrous Iron.

\begin{tabular}{|c|c|c|c|c|c|c|}
\hline & \multicolumn{2}{|c|}{ Normality. } & \multirow{2}{*}{$0.1 \mathrm{~N} \mathrm{FeCls}}$. & \multicolumn{3}{|c|}{ G. Fe. } \\
\hline & HCl. & $\mathrm{FF}$. & & Present. & Found. & Error. \\
\hline r....... & 2.50 & .. & . & 0.0057 & 0.0027 & -0.0030 \\
\hline $2 \ldots \ldots \ldots$ & 2.50 & . & 10 & 0.0057 & 0.0055 & $\longrightarrow 0.0002$ \\
\hline $3 \ldots \ldots \ldots$ & 0.25 & $\cdots$ & $\cdots$ & 0.0057 & 0.0057 & \pm 0.0000 \\
\hline $4 \ldots \ldots \ldots$ & 2.50 & $\cdots$ & . & 0.0113 & 0.0064 & -0.0049 \\
\hline $5 \ldots \ldots \ldots$ & 2.50 & $\cdots$ & . & 0.0170 & 0.0156 & $-0.001_{4}$ \\
\hline $6 \ldots \ldots \ldots$ & 2.50 & . & 10 & 0.0170 & 0.0170 & \pm 0.0000 \\
\hline $7 \ldots \ldots \ldots$ & 0.25 & . & . & 0.0170 & $0.017^{\circ}$ & \pm 0.0000 \\
\hline $8 \ldots \ldots \ldots$ & 2.50 & . & . & 0.0284 & 0.0275 & -0.0009 \\
\hline $9 \ldots \ldots \ldots$ & 2.50 & $\cdots$ & Io & 0.0284 & 0.0285 & +0.0001 \\
\hline 10.......... & 0.25 & . & . & 0.0284 & 0.0282 & -0.0002 \\
\hline II $\ldots \ldots \ldots$ & 2.50 & . & . & 0.0567 & 0.0564 & -0.0003 \\
\hline $12 \ldots \ldots \ldots$ & 2.50 & $\cdots$ & $\cdots$ & 0.0567 & 0.0565 & $\longrightarrow 0.0002$ \\
\hline $13 \ldots \ldots \ldots$ & 2.50 & .. & $\ldots$ & o. I I 34 & o. II35 & +0.0001 \\
\hline $14 \ldots \ldots \ldots$ & 2.50 & . & $\cdots$ & o. II 34 & o. 1135 & +0.0001 \\
\hline $15 \ldots \ldots \ldots$ & 0.50 & . & $\ldots$ & 0.0284 & 0.0285 & $+0.000 \mathrm{I}$ \\
\hline I6......... & 0.50 & . & . & 0.0567 & 0.0565 & -0.0002 \\
\hline $17 \ldots \ldots \ldots$ & 0.50 & . & $\ldots$ & 0.1418 & 0.1416 & -0.0002 \\
\hline $18, \ldots \ldots$ & 0.50 & . & . & 0.2268 & 0.2268 & $=0,0000$ \\
\hline $19 \ldots \ldots \ldots$ & . & 0.25 & . & 0.0057 & 0.0004 & -0.0053 \\
\hline $20 \ldots \ldots$ & . & 0.25 & 5 & 0.0057 & 0.0020 & -0.0037 \\
\hline $2 \mathbf{I} \ldots \ldots \ldots$ & . & 0.25 & 1 & 0.0057 & 0.0054 & $\multimap 0.0003$ \\
\hline $22 \ldots \ldots \ldots$ & . & 0.25 & . & 0.0113 & 0.0074 & -0.0039 \\
\hline $23 \ldots \ldots \ldots$ & . & 0.25 & 5 & 0.0113 & 0.0088 & -0.0025 \\
\hline $24 \ldots \ldots \ldots$ & . & 0.25 & 1 & 0.0113 & 0.0113 & \pm 0.0000 \\
\hline $25 \ldots \ldots \ldots$ & $\cdots$ & 0.50 & . & 0.0113 & 0.0034 & -0.0079 \\
\hline $26 \ldots \ldots \ldots$ & . & 0.50 & 5 & 0.0113 & 0.0074 & -0.0039 \\
\hline $27 \ldots \ldots \ldots$ & $\cdots$ & 0.50 & 1 & 0.0113. & 0.0114 & +0.0001 \\
\hline $28 \ldots \ldots \ldots$ & . & 1.00 & $\cdots$ & $0.0113^{\circ}$ & 0.0000 & -0.0113 \\
\hline $29 \ldots \ldots \ldots$ & . & $\dot{1} . \infty$ & 5 & 0.0113 & 0.0025 & $\longrightarrow 0.0088$ \\
\hline $30 \ldots \ldots$ & . & $1 . \infty$ & 1 & 0:01 I3 & 0.0084 & $\multimap 0.0029$ \\
\hline $31 \ldots \ldots \ldots$ & $\cdots$ & 2.00 & 5 & 0.0113 & 0.0004 & $\longrightarrow 0.0109$ \\
\hline $32 \ldots \ldots \ldots$ & $\cdots$ & 2.00 & 1 & 0.0113 & 0.0059 & -0.0054 \\
\hline $33 \ldots \ldots \ldots$ & . & 2.50 & $\mathrm{H}_{3} \mathrm{BO}_{3}$ Added & 0.0057 & 0.0057 & \pm 0.0000 \\
\hline $34 \ldots \ldots \ldots$ & $\cdots$ & 2.50 & " " & 0.0113 & 0.0114 & to.0001 \\
\hline $35 \ldots \ldots \ldots$ & . & 2.50 & $"$ & 0.0170 & $0.017 \mathrm{I}$ & to. $000 \mathrm{r}$ \\
\hline $36 \ldots \ldots \ldots$ & . & 2.50 & “ & 0.0284 & 0.0286 & to.0002 \\
\hline $37 \ldots \ldots \ldots$ & . & 2.50 & $"$ & 0.0284 & 0.0286 & +0.0002 \\
\hline $37 \ldots \ldots \ldots$ & $\cdots$ & 2.50 & " & 0.0567 & 0.0570 & +0.0003 \\
\hline
\end{tabular}

amounts of ferrous iron above 0.05 to o. Io g. can be titrated in even $2.5 \mathrm{~N}$ hydrochloric acid with safety. Experiments 15,16, I 7 and 18 show that $0.50 \mathrm{~N}$ acid is not detrimental when above $0.03 \mathrm{~g}$. of iron is being titrated. With less concentrations of acid much less ferrous iron could be accurately determined. The addition of ferric chloride to the fluoride solution has a tendency to improve the accuracy of the titration, yet not to a sufficient plate.

1 Drops of the ferric chloride solution were added to the ferricyanide on the spot 
degree to make the titration reliable (Experiments 19-32). The addition of a drop of ferric chloride to each drop of indicator on the spot plate before or after adding the drop of solution to be tested gave a much more accurate result in Experiments 21, 24, 27, 30 and 32. However, this required careful observance for the end point, which was a trifle obscure because of a very slight green tinge remaining after the titration was completed. However, the addition of boric acid removes the hydrofluoric acid, thus permitting an accurate titration of small amounts of ferrous iron to be made the same as when larger amounts are involved (Experiments $33-37$, see Table I).

From the preceding work it is recommended that not more than 5 or at the most Io cc. of concentrated hydrochloric acid be present in a volume of $200 \mathrm{cc}$. when small amounts of iron are to be titrated. Inasmuch as the use of ro cc. has no advantage over $5 \mathrm{cc}$., the latter amount should be employed. Boric acid when added to solutions containing hydrofluoric acid removes the latter and permits a quantitative determination of the iron to be made, whether the iron is present in small or large amounts.

\section{Analysis of Silicates for Ferrous Iron.}

In a previous article ${ }^{2}$ ferrous iron solutions containing fluoboric acid were shown to be quite stable in the presence of the air. Since the use of boric acid permits a correct titration to be made, the method previously outlined $^{2}$ can be modified, using dichromate instead of permanganate for the standard oxidizing solution. In Series IV the samples were decomposed according to the method referred to above, using ro $c c$. of hydrochloric acid, sp. gr. I.2 (sulfuric acid can be used if desired), and to to 20 cc. of hydrofluoric acid of $48 \%$ strength. A convenient strength of dichromate was found to be $\mathrm{r}$ cc. $=0.001 \mathrm{~g}$. FeO. A $0.05 \%$ solution of potassium ferricyanide was used as indicator on a spot plate, one drop being placed on each spot. When the end point had apparently been reached, two or three drops of the solution being titrated were used for the final test for ferrous iron in the spot plate reaction, thus increasing the accuracy of the test.

\begin{tabular}{|c|c|c|c|}
\hline \multirow{2}{*}{$\begin{array}{l}\text { Silicate } \\
\text { number. }\end{array}$} & \multirow{2}{*}{$\begin{array}{l}\text { Sample. } \\
\text { Grams. }\end{array}$} & \multicolumn{2}{|c|}{ Per cent. FeO found by } \\
\hline & & $\mathrm{KMnO}_{4}$ & $\mathrm{~K}_{2} \mathrm{Cr}_{2} \mathrm{O} 7$. \\
\hline $\mathbf{I} \ldots$ & I & I. IO & I.02 \\
\hline $2 \ldots$ & 2 & $0.5 \mathrm{I}$ & 0.51 \\
\hline $3 \ldots$ & I & 13.80 & 13.70 \\
\hline $4 \ldots$ & I & $14.4 \mathrm{I}$ & 14.38 \\
\hline $5 \ldots$ & $\mathbf{r}$ & 6.49 & 6.40 \\
\hline $6 \ldots$ & $\mathbf{I}$ & 5.47 & 5.47 \\
\hline
\end{tabular}

i Barnebey, This Journal, 37, rigr (rgr5).

2 Loc. cit. 
In the analysis of Samples $I$ and 2 the solutions had to be filtered to remove suspended organic matter in order to permit titration with permanganate, yet no trouble was encountered in titrating with dichromate without filtration. Samples $3^{-6}$ inclusive did not contain organic matter. All of these results are average results of closely agreeing duplicating analyses.

\section{Conclusions.}

r. The concentration of acid should be small when titrating small amounts of iron with dichromate, using ferricyanide as indicator on the spot plate. If the concentration is quite large ferric chloride should be added to give a sharper color change on the spot plate.

2. Boric acid counteracts the influence of hydrofluoric acid in the dichromate titration of ferrous iron and hence addition of this reagent to the hydrofluoric acid extraction of the silicate yields a solution in which the ferrous iron can be accurately titrated with dichromate, using ferricyanide as indicator on a spot plate.

Madison, Wisconsin.

\section{NOTE.}

Use of Acetone for Drying Chemical Utensils.-Acetone is miscible in all proportions with water. It has a boiling point of $56^{\circ}$. On account of these two properties acetone is an excellent substance to use as a wash to facilitate the drying of glassware, especially flasks, bottles, etc. After cleaning and rinsing with water the vessel is allowed to drain a short time, then sufficient acetone is added to give a good wash. After again draining a few seconds the remaining acetone is removed by drawing air through the vessel by inserting a glass tube which is connected to suction, or by the application of heat. The author has found the use of acetone very serviceable, replacing the use of alcohol to remove the water, then ether to remove the alcohol. The acetone has the merit of being cheaper than either alcohol or ether at the present time.

O. L. BARNEBEY.

University of Wisconsin, Madison.

[CONTRIBUTION FROM THE ChEMICAL LABORATORY OF THE UNIVERSITY OF SOUTH DAKOTA.]

\section{DERIVATIVES OF PHENYL ETHER.}

Bx Alargid N. Cooz and Frank F. Sherwood.

Received June 9. 1915.

2-Nitro-4'-methyl phenyl ether $\left(\mathrm{NO}_{2} \cdot \mathrm{C}_{6} \mathrm{H}_{4} \mathrm{OC}_{6} \mathrm{H}_{4} \cdot \mathrm{CH}_{3}\right)$ was first prepared by one of the authors ${ }^{1}$ of this paper about sixteen years ago and some of its derivatives were prepared and studied. Subsequently some other compounds of an analogous nature and corresponding derivatives

${ }^{1}$ Am. Chem. J., 24, 525-529 (1900). 